Goldschmidt 2021 Abstract

https://doi.org/10.7185/gold2021.6909

\section{Biomineralization of electroactive Mn- oxides by the Mn(II) oxidizer Pseudomonas putida for electrochemical energy storage.}

LAURA GALEZOWSKI ${ }^{1}$, NADIR RECHAM ${ }^{2,3}$, JENNYFER MIOT $^{1}$, FÉRIEL SKOURI-PANET ${ }^{1}$, DOMINIQUE LARCHER $^{2,3}$ AND FRANCOIS GUYOT ${ }^{1,4}$

${ }^{1}$ Institut de Minéralogie, Physique des Matériaux et Cosmochimie, CNRS UMR 7590

${ }^{2}$ Laboratoire de Réactivité et Chimie des Solides, CNRS UMR 7314

${ }^{3}$ Réseau sur le Stockage Electrochimique de l'Energie (RS2E), FR CNRS 3459, France

${ }^{4}$ Museum National d'Histoire Naturelle et Institut Universitaire de France (IUF)

Presenting Author: laura.galezowski@upmc.fr

Microbial metabolisms play an important role in the redox cycle of manganese in the environment. A diversity of Mn(II) oxidizing organisms leads to the biomineralization of manganese oxides with specific textures and metal sequestration properties with potential technological applications, e.g. for energy storage. The ability to reversibly host cations (especially alkaline) has been extensively studied for abiotic Mn oxides and used for the production of electrode materials (e.g. alkaline $\mathrm{Zn} / \mathrm{MnO}_{2}$ or $\mathrm{Li} / \mathrm{MnO}_{2}$ cells). It is therefore conceivable to use the ability of certain bacteria to produce manganese oxides to develop an alternative method of producing electrode materials for energy storage. The control of their phase and texture under ambient conditions can provide environmentally relevant synthesis pathways. Moreover, the mineralisation induced by the microbes produces a specific texture of the biominerals, which enables electrochemical performance to be maintained[1,2]. Here, we evaluated the mechanisms of Mn oxidation (including kinetics of $\mathrm{Mn}(\mathrm{II})$ oxidation) by the Mn(II)-oxidizer Pseudomonas putida to produce manganese oxides in planktonic conditions $v s$. in biofilm. Manganese speciation, biominerals crystallography and texture as well as organic matter content were determined by a combination of X-ray absorption spectroscopies, electron microscopies, synchrotron-based X-ray absorption spectroscopies and thermogravimetric analyses coupled to mass spectrometry. Electrochemical activity of the biominerals were evaluated in battery configuration vs. metallic Li, showing very appealing properties (voltage, capacity, reversibility, power capability). Under optimized growth conditions of biomineralized culture, mineralogical characterizations revealed the formation of a poorly crystalline birnessite, $\mathrm{MnO}_{2}$. Electrochemical measurements in a half-battery cell vs. $\mathrm{Li}(0)$ revealed the electrochemical signature of the $\mathrm{Mn}^{3+} / \mathrm{Mn}^{4+}$ redox couple[3]. The particular texture of this composite material likely enhances ionic conduction. Thus, our study sheds light on the reactivity of these electroactive Mn-biominerals that are widespread in the environment. In addition, these results open an alternative route for the synthesis of performant electrode
1. Mirvaux, Recham, Miot, Courty, Bernard, Beyssac, Davoisne, Sougrati, Demortière, Guyot, Tarascon, and Larcher (2016), J. Electrochem. Soc. 163, A2139.

2. Miot, Recham, Larcher, Guyot, Brest, and Tarascon (2014), Energy \& Environmental Science 7, 451.

3. Galezowski, Recham, Larcher, Miot, Skouri-Panet, and Guyot (2020), Front. Microbiol. 11. 